\title{
PERANCANGAN SISTEM PENGUKURAN KINERJA DENGAN METODE INTEGRATED PERFORMANCE MEASUREMENT SYSTEMS (IPMS) (Studi Kasus: Program Studi Teknik Industri Universitas PGRI Adi buana Surabaya)
}

\author{
Oleh : Yunia Dwie Nurcahyanie *)
}

\begin{abstract}
Abstrak
Untuk menjamin kualitas pendidikan di Program Studi Teknik Industri Universitas PGRI Adi Buana surabaya, diperlukan sebuah rancangan sistem pengukuran kinerja (SPK) yang terintegrasi dengan metode IPMS (Integrated Performance Measurement Systems). Dengan metode IPMS, Key Performance Indicators (KPI) Program Studi Teknik Industri ditentukan berdasarkan stakeholder requirement melalui empat tahapan yaitu; identifikasi stakeholder requirement, external monitor, penetapan objectives, dan identifikasi KPIs. Hasil perancangan SPK di Program Studi Teknik Industri Universitas PGRI Adi Buana Surabaya, dapat mengidentifikasi 26 KPIs yang dikelompokkan dalam 9 kriteria kinerja Program Studi Teknik Industri, yaitu; kurikulum, mahasiswa, finansial, SDM, administrasi akademik, proses belajar mengajar, lulusan, evaluasi dan pengendalian, dan masyarakat
\end{abstract}

Kata Kunci : Sistem Pengukuran Kinerja, IPMS, Teknik Industri UNIPA

\section{PENDAHULUAN}

Pentingnya pengukuran kinerja tidak hanya diperlukan dan dilakukan dalam dunia bisnis tetapi juga dalam dunia pendidikan. Demikian pentingnya pengukuran kinerja dalam pengelolaan Perguruan Tinggi atau dunia pendidikan, maka Direktorat Jenderal Pendidikan Tinggi memasukkannya dalam format manajemen baru yang bertujuan untuk meningkatkan kualitas pendidikan secara berkelanjutan. Peningkatan kualitas pendidikan secara berkelanjutan dilakukan dengan memasukkan penilaian, akreditasi dan evaluasi diri institusi yang dilakukan terhadap perguruan tinggi baik negeri maupun swasta (Soehendro, 1996).

Dengan membentuk Badan Akreditasi Nasional (BAN), Departemen Pendidikan Nasional berusaha mengawasi dan membina mutu pendidikan tinggi. Mutu Pendidikan sebagai kewajiban konstitusinya dengan menjadikan beberapa indikator kinerja dari suatu Perguruan Tinggi sebagai parameternya. Terlepas dari manfaat yang diperoleh, sistem penilaian kinerja Badan Akreditasi Nasional (BAN) masih terdapat beberapa kelemahannya. Kelemahan yang utama adalah karena lebih menekankan pada penilaian terhadap kriteria dan persyaratan perizinan atau pelaksanaan Perguruan Tinggi, sehingga lebih bersifat administratif. Padahal pengenalan kualitas kinerja untuk merencanakan kegiatan fungsional menuju peningkatan kualitas yang berkelanjutan masih belum terwujud sepenuhnya (Vanany, 1999). Agar kualitas kinerja berkelanjutan, perlu dikorelasikan dengan strategi jangka panjang dengan merujuk pada visi, misi yang telah ditetapkan. Menurut Brojonegoro
(1999) dalam makalah pada Teaching Improvement Workshop, menekankan agar perguruan tinggi di Indonesia menyusun rencana strategis jangka panjang untuk merealisasikan visi dan misi yang telah ditetapkan. Dari rencana strategis tersebut kemudian diturunkan menjadi rencana operasional yang diimplementasikan setiap tahun. Dengan adanya rencana tersebut maka keterkaitan antara program dengan target pencapaian dapat diketahui dan ini yang merupakan salah satu indikator kinerja perguruan tinggi. Belum adanya sistem kearsipan yang rapi dan teratur, tidak ada sistem database yang memadai, sistem administrasi yang belum teratur, belum efektifnya evaluasi yang berkelanjutan dari kesesuaian kurikulum dengan kualitas lulusan yang dibutuhkan oleh pemakai lulusan, tidak adanya kontrol terhadap implementasi kurikulum dan silabus pada proses belajar mengajar, dan lain-lain. Dengan demikian banyak dan kompleknya permasalahan yang ada, maka Program Studi berusaha mengambil langkahlangkah prioritas dalam menyelesaikan permasalahan dan untuk meningkatkan kinerjanya. Ada tiga prioritas yang akan dilakukan untuk meningkatkan kinerja (performance) Program Studi Teknik Industri yaitu: pembenahan manajemen pelayanan Program Studi, manajemen pembelajaran, manajemen hubungan dengan dunia luar. 
Untuk mengukur tingkat keberhasilan, efisiensi, dan efektivitas dari kegiatan yang dilaksanakan, diperlukan sebuah sistem pengukuran kinerja (SPK) Program Studi dan implementasinya. Sampai saat ini sistem pengukuran kinerja dan implementasinya di Program Studi Teknik Industri Universitas PGRI Adibuana belum ada. Berdasarkan uraian di atas, maka perlu dilakukan perancangan dan implementasi sistem pengukuran kinerja di Program Studi Teknik Industri Universitas PGRI Adibuana Surabaya. Dengan perancangan sistem pengukuran kinerja dan implementasinya diharapkan dapat mewujudkan manajemen Program Studi Teknik Industri yang terintegrasi dengan jaminan mutu. Pada dasarnya penelitian ini bertujuan untuk merancang sistim pengukuran kinerja di Program Studi Teknik Industri Universitas PGRI Adibuana Surabaya. Secara lebih detail tujuan dari penelitian ini adalah sebagai berkut:

1. Menentukan ukuran-ukuran kinerja (measures) yang biasa disebut KPI.

2. Memperoleh rancangan/cetak biru SPK Program Studi Teknik Industri Universitas PGRI Adibuana Surabaya.

\section{INTEGRATED PERFORMANCE MEASURE- MENT SYSTEM (IPMS)}

Integrated Performance Measurement System, yang selanjutnya disebut IPMS merupakan sistem baru pengukuran kinerja yang dibuat di Centre for Strategic Manufacturing, University of Strathclyde, Glasgow (Suwignjo, 2000), dengan tujuan mendeskripsikan dalam arti yang tepat bentuk dari integrasi, efektif dan efisien SPK, sehingga untuk mencapai tujuan tersebut maka dideskripsikan sebagai berikut:

1. Komponen pokok dari sistem pengukuran kineja.

2. Membuat garis arahan pengukuran kinerja terbaik yang sebaiknya digunakan.

Model IPMS membagi level bisnis suatu organisasi menjadi 4 level seperti Gambar 1, yaitu: Business (Corporate - Bisnis Induk), Business Unit (Unit Bisnis), Business Process (Proses Bisnis), dan Activity (Aktivitas Bisnis). Sehingga perancangan SPK dengan model IPMS harus mengikuti tahapan-tahapan sebagai berikut: identifikasi stakeholder dan requirement, melakukan External Monitor (Benchmarking), menetapkan objectives bisnis, mendefinisikan measures/KPI, melakukan validasi $\mathrm{KPI}$, dan spesifikasikan $\mathrm{KPI}$.

\subsection{Stakeholder Requirement}

Pada tiap-tiap level bisnis (organisasi) harus diketahui siapa saja stakeholder-nya atau pihak-pihak yang berkepentingan pada bisnis tersebut. Selanjutnya diidentifikasikan permintaan/keinginan (requirement) mereka terhadap bisnis yang diistilahkan dengan Stakeholder Requirement. Stakeholder dapat meliputi; pemegang saham/pemilik, lingkungan sosial, pegawai/karyawan, pemerintah/instansi lain.

\subsection{External Monitor}

External monitor dilakukan untuk mengetahui posisi organisasi terhadap pesaing dan performansi/kinerja kelas dunia.

\subsection{Objectives}

Penyusunan tujuan (objectives) harus didasarkan pada keterlibatan dan prioritas perkembangan kebutuhan bersama dengan target dan skala waktu yang tepat. Menurut Suwignjo (2000) dengan menggunakan cause effect tool seperti RONA, ROI trees dapat memberikan keterangan bahwa tujuan diperoleh melalui analisa yang akurat. Tujuan seharusnya juga didasarkan pada pemikiran sejumlah masukan, yaitu; permintaan stakeholder, praktek dan performansi bisnis kelas dunia, competitif gaps dan rencana pesaing, tingkat performansi dimana organisasi mampu mencapainya dengan berbagai batasan yang ada disebut target realistis, tingkat performansi dimana organisasi memiliki kemampuan untuk mencapainya dengan menghilangkan berbagai batasan yang ada yang dikatakan sebagai target potensial (Suwignjo, 2000).

\subsection{Performance Measures}

Suatu bisnis (organisasi) seharusnya memiliki pengukuran performansi yang benarbenar menunjukkan tingkat performansi yang dicapai, serta mampu menunjukkan seberapa berhasil pencapaian tujuan pada tiap level. Pengukuran performansi untuk setiap bisnis memiliki perbedaan, oleh sebab itu diperlukan kejelian dan pemahaman yang baik dari bisnis agar diperoleh pengukuran performansi yang benar.

Untuk memperoleh ukuran performansi atau KPI yang benar perlu dilakukan validasi terhadap KPI yang dibuat. Kemudian apabila KPI tersebut sudah valid, maka KPI dispesifikasikan untuk memudahkan dalam proses pengukurannya. Proses spesifikasi KPI ini dilakukan untuk mengetahui deskripsi yang jelas tentang KPI, tujuan, keterkaitan dengan objectives, target dan ambang batas, formula/cara mengukur KPI, frekuensi pengukuran, frekuensi review, siapa yang mengukur, dan apa yang mereka kerjakan. 


\section{PERANCANGAN SPK}

Proses perancangan SPK dilaksanakan berdasarkan kerangka kerja IPMS dan pendekatan sistem organisasi Program Studi Teknik Industri Universitas PGRI Adibuana Surabaya dengan langkah-langkah sebagai berikut:

1. Stakeholder requirement.

2. External Monitoring.

3. Menentukan tujuan - tujuan (objectives) Program Studi.

4. Menentukan ukuran - ukuran kinerja (measures) yang biasa disebut KPI.

5. Melakukan validasi KPI.

6. Spesifikasi KPI.

7. Pembobotan KPI.

8. Scoring system SP

\subsection{Identifikasi Stakeholder Require-} ment
Sebelum mengidentifikasi stakeholder requirement, pertama-tama dilakukan pembagian level bisnis/organisasi menjadi empat level bisnis sesuai dengan kerangka kerja IPMS dan pendekatan sistim organisasi Program Studi seperti ditunjukkan pada Gambar 1 dan 2.Berdasarkan pendekatan sistem dan pembagian level organisasi dapat diketahui stakeholder Program Studi adalah pihak universitas/fakultas, manajemen Program Studi, mahasiswa, dosen, karyawan, industri, dan masyarakat. Dari masing-masing stakeholders tersebut kemudian diidentifikasi requirementnya. Setelah semua requirement (keinginan) dari masing-masing stakeholder ditulis, kemudian dilakukan seleksi untuk melihat adanya kesamaan requirement dari masingmasing stakeholder. Berdasarkan hasil seleksi maka dapat diidentifikasi 15 requirement seperti ditampilkan dalam gambar 1 .

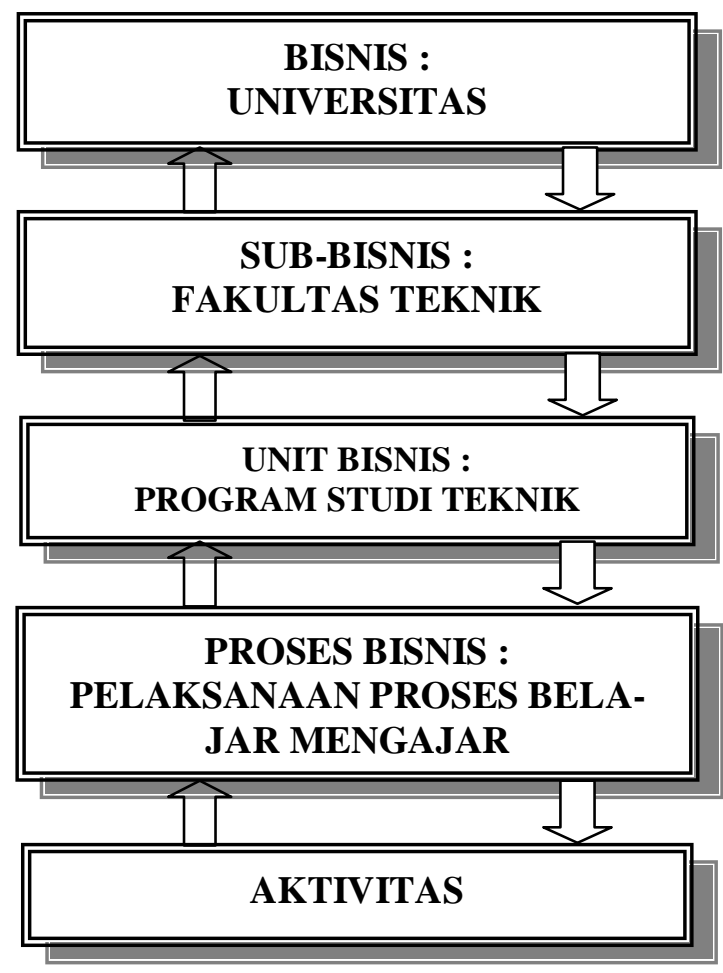

Gambar 1. Pembagian Level Organisasi Program Studi Teknik Industri 


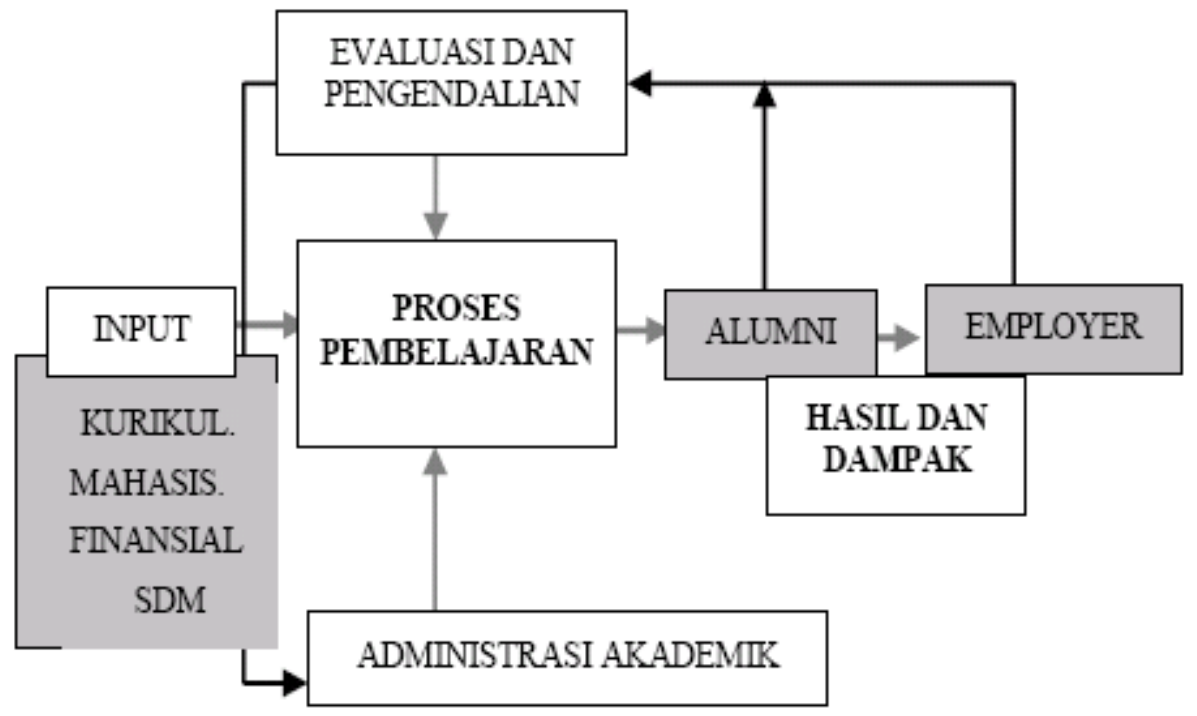

\section{Gambar 2. Pendekatan Sistem Organisasi Program Studi Teknik Industri}

Setelah semua stakeholder requirement diidentifikasi, kemudian dilakukan seleksi untuk melihat adanya kesamaan dari requirement. Berdasarkan hasil seleksi maka didapat 15 requirement sebagai berikut

1. Proses belajar mengajar yang berjalan dengan baik dan berkualitas

2. Tersedianya LCD, komputer dan AC pada setiap ruang kuliah

3. Peningkatan kualitas dosen dan karyawan

4. Ketersediaan diktat mata kuliah dan petunjuk praktikum

5. Peningkatan pengetahuan dan pemahaman mahasiswa terhadap materi kuliah

6. Lulusan dapat melanjutkan studi ke Program Pasca Sarjana

7. Semakin meningkatnya minat baca mahasiswa

8. Kualitas penelitian dosen dan mahasiswa semakin meningkat

9. Waktu kelulusan yang lebih cepat dengan IP yang baik

10. Menghasilkan lulusan yang peduli terhadap masyarakat
11. Kemudahan mendapat tempat KKN

12. Pengelolaan keuangan program studi yang bertanggung jawab

13. Pengurusan kenaikan pangkat yang lancar

14. Kesejahteraan dosen dan karyawan diperhatikan

15. Terlaksananya setiap program yang direncanakan

\subsection{External Monitoring}

External monitoring/benchmarking dilakukan dengan studi terhadap beberapa pustaka seperti ; Rencana Strategis Universitas PGRI Adi Buana Surabaya tahun 2003 (Universitas PGRI Adi Buana Surabaya, 2003) , Penyusunan dan Pengembangan Kurikulum Program Studi Teknik Industri Universitas PGRI Adi Buana Surabaya (Rusdiyantoro, dkk, 2000), Proposal Hibah A1 (Program Studi Teknik Industri, 2005), Penilaian Akreditasi Program Studi Teknik Industri Tahun 2005. 


\section{Tabel 1. Identifikasi Stakeholder Requirement}

\begin{tabular}{|c|c|}
\hline Stakeholder & Requirement \\
\hline Universitas/Fakultas & $\begin{array}{l}\text { 1. Proses belajar mengajar yang berjalan } \\
\text { dengan baik dan berkualitas } \\
\text { 2. Peningkatan kualitas dosen dan karyawan } \\
\text { 3. Menghasilkan lulusan yang peduli terhadap } \\
\text { masyarakat }\end{array}$ \\
\hline Program Studi & $\begin{array}{l}\text { 1.Proses belajar mengajar yang berjalan } \\
\text { dengan baik dan berkualitas } \\
\text { 2. Tersedianya LCD, komputer dan AC pada } \\
\text { setiap ruang kuliah } \\
\text { 3. Peningkatan kualitas dosen dan karyawan } \\
\text { 4. Semakin meningkatnya minat baca } \\
\text { mahasiswa } \\
\text { 5. Kualitas penelitian dosen dan mahasiswa } \\
\text { semakin meningkat } \\
\text { 6. Waktu kelulusan yang lebih cepat dengan } \\
\text { IP yang baik } \\
\text { 7. Menghasilkan lulusan yang peduli terhadap } \\
\text { masyarakat } \\
\text { 8. Terlaksananya setiap program yang } \\
\text { direncanakan } \\
\text { 9. Pengelolaan keuangan program studi yang } \\
\text { bertanggung jawab }\end{array}$ \\
\hline Dosen & $\begin{array}{l}\text { 1. Tersedianya LCD, komputer dan AC pada } \\
\text { setiap ruang kuliah } \\
\text { 2. Peningkatan kualitas dosen dan karyawan } \\
\text { 3. Ketersediaan diktat mata kuliah dan } \\
\text { petunjuk praktikum } \\
\text { 4. Peningkatan pengetahuan dan pemahaman } \\
\text { mahasiswa terhadap materi kuliah } \\
\text { 5. Kualitas penelitian mahasiswa dan dosen } \\
\text { semakin meningkat } \\
\text { 6.Pengurusan kenaikan pangkat yang lancar } \\
\text { 7. Kesejahteraan dosen dan karyawan } \\
\text { diperhatikan }\end{array}$ \\
\hline Karyawan & $\begin{array}{l}\text { 1. Peningkatan kualitas dosen dan karyawan } \\
\text { 2. Pengurusan kenaikan pangkat yang lancar } \\
\text { 3. Kesejahteraan dosen dan karyawan } \\
\text { diperhatikan }\end{array}$ \\
\hline Mahasiswa & $\begin{array}{l}\text { 1. Proses belajar mengajar yang lebih baik } \\
\text { dan berkualitas } \\
\text { 2. Tersedianya LCD, Komputer dan AC di } \\
\text { setiap ruang kuliah } \\
\text { 3. Ketersediaan diktat mata kuliah dan } \\
\text { petunjuk praktikum } \\
\text { 4. Lulusan dapat melanjutkan studi ke } \\
\text { program pasca sarjana } \\
\text { 5. Waktu kelulusan yang lebih cepat dan IP } \\
\text { yang lebih baik } \\
\text { 6. Kemudahan mendapat tempat KKN }\end{array}$ \\
\hline Masyarakat & $\begin{array}{l}\text { 1.Menghasilkan lulusan yang peduli terhadap } \\
\text { masyarakat }\end{array}$ \\
\hline
\end{tabular}




\subsection{Penetapan Objective}

Berdasarkan stakeholder requirement, kemudian ditetapkan objectives-nya. Hasilnya didapatkan 20 objective yang akan dilakukan oleh program studi sebagai upaya untuk me- menuhi stakeholder requirement. Selengkapnya dapat dilihat pada tabel 2 .

\subsection{Penetapan KPI}

Dari objective yang ada, di identifikasi sebanyak $26 \mathrm{KPI}$ seperti ditunjukkan dalam Tabel 2.

Tabel 2. objective dan KPI dari masing-masing Requirement

\begin{tabular}{|c|c|}
\hline Requirement & Objectives \\
\hline Req 1 & $\begin{array}{l}\text { 1. Meningkatkan kuantitas proses } \\
\text { belajar mengajar } \\
\text { 2. Pembuatan SAP, Silabus, untuk } \\
\text { setiap mata kuliah } \\
\text { 3. Melakukan pantauan apakah } \\
\text { proses belajar mengajar sesuai } \\
\text { dengan SAP, silabus }\end{array}$ \\
\hline Req 2 & $\begin{array}{l}\text { 4. Menyediakan LCD dan AC untuk } \\
\text { setiap ruang kuliah }\end{array}$ \\
\hline Req 3 & $\begin{array}{l}\text { 5. Meningkatkan kualitas dosen } \\
\text { 6. Meningkatkan kualitas karyawan }\end{array}$ \\
\hline Req 4 & $\begin{array}{l}\text { Pembuatan diktat dan petunjuk } \\
\text { praktikum untuk peningkatan } \\
\text { kuaitas pendidikan }\end{array}$ \\
\hline Req 5 & $\begin{array}{l}\text { 8. Mahasiswa diberi tugas } \\
\text { kelompok/individu tentang studi } \\
\text { kasus }\end{array}$ \\
\hline Req 6 & $\begin{array}{l}\text { 8. Mengembangkan kurikulum } \\
\text { sesuai kebutuhan mahasiswa } \\
\text { untuk studi lanjut dan } \\
\text { berorientasi pada pekerjaan }\end{array}$ \\
\hline Req 7 & $\begin{array}{l}\text { 9. Menambah koleksi buku } \\
\text { perpustakaan program studi }\end{array}$ \\
\hline
\end{tabular}

Req 8

Req 9

Req 10
11. Bantuan dana dari program studi untuk melakukan penelitian

12. Mempresentasikan hasil penelitian pada seminar nasional \& internasional

13. Melibatkan mahasiswa dalam penelitian dosen

14. Mendorong mahasiswa untuk mencapai waktu studi yang pendek dengan IP yang baik

15. Mahasiswa dilibatkan dalam kegiatan pengabdian kepada masyarakat

\section{Key Performance Indicator}

1. Presentase kehadiran dosen

2. Presentase mata kuliah yang sudah memiliki silabus, SAP

3. Presentase perkuliahan yang sesuai dengan SAP, silabus tiap semester

4. Rasio LCD dan ruang kuliah

5. Rasio AC dengan ruang kuliah

6. Presentase dosen berpendidikan lanjut

7. Rasio dosen yang ikut course outline

8. Presentase karyawan yang mengikuti pelatihan

9. Rasio diktat dan mata kuliah

10. Rasio petunjuk praktikum dan mata kuliah

11. Jumlah tugas untuk setiap mata kuliah

12. Jumlah lulusan yang melanjutkan ke Program Pasca Sarjana

13. Rasio referensi terhadap mahasiswa

14. Jumlah pengunjung perpustakaan per hari

15. Presentase penelitian dosen yang mendapatkan dana dari program studi

16. Presentase penelitian dosen yang diterbitkan dalam jurnal ilmiah

17. Presentase mahasiswa yang terlibat dalam penelitian dosen

18. Rasio lama studi mahasiswa

19. IPK rata-rata lulusan

20. Jumlah kegiatan pengabdian kepada masyarakat

21. Presentase mahasiswa yang terlibat dalam kegiatan pengabdian kepada masyarakat 


\begin{tabular}{|c|c|c|}
\hline Requirement & Objectives & Key Performance Indicator \\
\hline Req 11 & $\begin{array}{l}\text { 16. Memberikan kemudahan kepada } \\
\text { masyarakat untuk mendapatkan } \\
\text { tempat KKN }\end{array}$ & $\begin{array}{l}\text { 22. Waktu rata-rata mahasiswa } \\
\text { mendapat tempat KKN }\end{array}$ \\
\hline Req 12 & $\begin{array}{l}\text { 17. Pembuatan laporan keuangan } \\
\text { program studi secara rutin }\end{array}$ & $\begin{array}{l}\text { 23. Presentase laporan keuangan } \\
\text { yang tepat waktu }\end{array}$ \\
\hline Req 13 & $\begin{array}{l}\text { 18. Mempercepat proses penilaian } \\
\text { angka kredit }\end{array}$ & $\begin{array}{l}\text { 24. Rasio penilaian angka kredit } \\
\text { yang diselesaikan }<1 \text { bulan }\end{array}$ \\
\hline Req 14 & $\begin{array}{l}\text { 19. Ketepatan waktu pembayaran } \\
\text { gaji dan honor }\end{array}$ & $\begin{array}{l}\text { 25. Presentase pembayaran gaji } \\
\text { dan honor yang tepat waktu }\end{array}$ \\
\hline Req 15 & $\begin{array}{l}\text { 20. Mengadakan pertemuan untuk } \\
\text { sosialisasi program-program } \\
\text { yang direncanakan }\end{array}$ & $\begin{array}{l}\text { 26. Presentase } \\
\text { terlaksana }\end{array}$ \\
\hline
\end{tabular}

\subsection{Validasi KPI}

KPI yang teridentifikasi kemudian dibuat dalam bentuk hirarki SPK dengan level teratas kinerja Program Studi Teknik Industri, level dibawahnya adalah kriteria kinerja
Program Studi (berdasarkan kriteria evaluasi yang tercantum didalam renstra program studi), dan level paling bawah adalah KPI seperti Gambar 3.

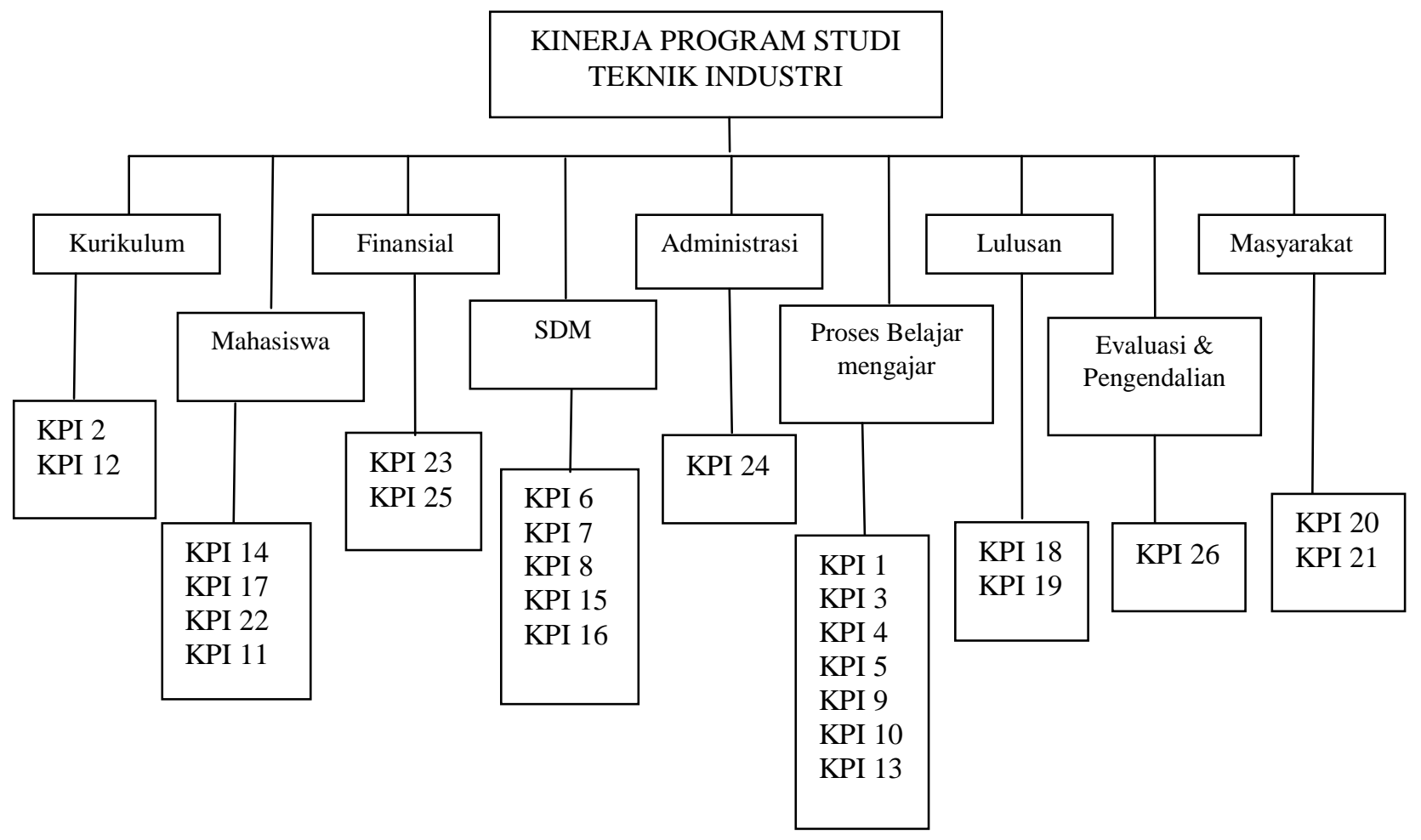

Gambar 3. Hirarki Kinerja Program Studi Teknik Industri

\section{Spesifikasi KPI}

Spesifikasi KPI ini menjelaskan tentang KPI, deskripsi, tujuan, target, formula/cara mengukur $\mathrm{KPI}$, frekuensi pengukuran, frekuensi review, siapa yang mengukur, sumber data dan pemilik KPI. 


\begin{tabular}{ll}
\hline KPI1 & Rata-rata presentase kehadiran dosen \\
\hline DESKRIPSI & Rata-rata kehadiran dosen pada setiap proses belajar- \\
& mengajar \\
TUJUAN & Meningkatkan kuantitas proses belajar mengajar \\
TARGET & Dosen selalu hadir sesuai jadwal belajar mengajar yang \\
& ditentukan \\
FORMULA & Jumlah perkuliahan $/ 18\} \times 100 \%$ \\
FREKUENSI PENGUKURAN & Setiap akhir semester \\
FREKUENSI REVIEW & Setiap akhir semester \\
SIAPA YANG MENGUKUR & Tim Evaluasi Fakultas \\
SUMBER DATA & Daftar kehadiran dosen di Program Studi \\
PEMILIK KPI & Fakultas Teknik \\
\hline
\end{tabular}

\subsection{Pembobotan KPI}

Setelah terbentuk indikator-indikator kinerja(KPI) Program Studi Teknik Industri Universitas PGRI Adibuana Surabaya maka langkah berikutnya adalah mencari bobot dari masing-masing-masing KPI berdasarkan hirarki kinerja yang terbentuk dengan menggunakan pendekatan Analitic Hierarchy Process, AHP (Saaty, 1991). Alat yang digunakan untuk mengetahui bobot adalah berupa kuisioner. Kuesioner tersebut bersifat tertutup yang berisikan kriteria-kriteria dan KPI yang diberikan pada satu orang ahli, yaitu Ketua Program Studi Teknik Industri untuk memberikan bobot dengan penilaian berupa perbandingan berpasangan (pairwise).

Data yang diperoleh dari kuisioner kemudian diolah dengan menggunakan program komputer berupa Software Expert Choise Version 9.0 (1995). Dari sembilan kriteria yang ada dilihat kriteria mana yang memiliki nilai terbesar. Ini berarti bahwa kriteria yang terbesar tersebut harus mendapatkan perhatian yang besar dari Program Studi untuk dapat meningkatkan kinerjanya. Kemudian dilihat kriteria mana yang memiliki bobot paling kecil, artinya bahwa kriteria tersebut belum begitu mendesak untuk ditindaklanjuti dalam rangka meningkatkan kinerja Program Studi.

\subsection{Scoring System SPK}

Pencapaian Kinerja Jurusan Teknik Industri sangat bergantung pada hasil (score) yang dicapai oleh masing-masing indikator (KPI). Untuk mengetahui nilai pencapaian terhadap target dari masing-masing KPI perlu dibuatkan scoring system seperti contoh Gam- bar 4. Scoring system ini harus dibuat bersama-sama dengan traffic light system untuk memberikan rambu-rambu atau tanda, apakah nilai score dari KPI tersebut perlu perbaikan (improvement) atau tidak. Dalam rancangan ini traffic light system dibuat menggunakan tiga warna yaitu; warna merah, kuning, dan hijau. Warna merah menandakan score dari KPI tidak mencapai target atau di bawah target dengan score 0-55. Warna kuning memberikan indikasi bahwa score yang dicapai perlu ditingkatkan dengan memberikan batasan $56-79$. Terakhir warna hijau menandakan bahwa score yang didapat sesuai dengan target yaitu; score 80 - 100. Setelah traffic light system ditentukan, kemudian dilakukan pengukuran untuk menghitung score masing-masing KPI berdasarkan target dan pencapaiannya.

\section{SIMPULAN}

1. Dengan metode ini dapat diidentifikasi 26 (duapuluh enam) KPI (Key performance Indicators) dari Program Studi Teknik Industri yang dikelompokkan kedalam sembilan kriteria kinerja Jurusan yaitu; kurikulum, mahasiswa, finansial, SDM, administrasi akademik, proses belajar mengajar, lulusan, evaluasi dan pengendalian, dan masyarakat.

2. Dihasilkan sebuah rancangan dan cetak biru (blue print) sistem pengukuran kinerja (SPK) Jurusan Teknik Industri yang dapat memberikan informasi kepada stakeholder dan pengambil keputusan untuk mengukur dan mengevaluasi kinerjanya dari masingmasing tingkatan organisasi Program Studi Teknik Industri Universitas PGRI Adi Buana Surabaya. 


\section{DAFTAR PUSTAKA}

Artley, Will and Stroh, Suzanne. 2001. The PerformanceManagement Handbook: Establishing an Integrated Performance Measurement System. Performance-Based Management Special Interest Group (PBM SIG), <http://www.orau.gov/pbm

Brodjonegoro, S., S.1999, Beberapa Pemikiran dalam Rangka Peningkatan Mutu dan Daya Saing Perguruan Tinggi. Materi TIW, Universitas Brawijaya, Malang.

Bititci, U.S., Carrie, Allan S., McDevitt, Liam (1997), Integrated Performance Measurement System: a Development Guide, International Journal of Operation and Production management, Vol. 17, No.5, 1997

Neely A, Gregory M and Platts K.1995. Performance Measurement System Design : A Literature. University of Cambridge, Cambridge Research Group, Mill Lane, Cambridge

Jurusan Teknik Industri. 2005. Proposal Hibah A1

Rusdiantoro. 2000. Penyusunan dan Pengembangan Kurikulum Program Studi Teknik Industri Universitas PGRI Adi Buana Surabaya

Suwignjo, P. 2000. Sistem Pengukuran Kinerja: Sejarah Perkembangan dan Agenda Penelitian ke Depan, Proceeding Seminar Nasional Performance Management, Bagian C, Hotel Wisata, Jakarta.

Universitas PGRI Adi Buana Surabaya .2003. Rencana Strategis Universitas PGRI Adi Buana Surabaya tahun 2003

Vanany, I.1999. Perancangan Sistim Pengukuran Kinerja pada Perguruan Tinggi dengan Menggunakan Metode Balanced Scorecard, Tesis Program Pascasarjana Teknik Industri- ITS, Surabaya. 